\title{
Dessie Health Science College Store Management System
}

\author{
Esmael Seid Ali \\ Department of Basic Health Science, Dessie Health Science College, Dessie, Ethiopia
}

\section{Email address:}

esmael228@gmail.com

\section{To cite this article:}

Esmael Seid Ali. Dessie Health Science College Store Management System. Internet of Things and Cloud Computing. Vol. 5, No. 1, 2017, pp. 1-6. doi: 10.11648/j.iotcc.20170501.11

Received: October 25, 2016; Accepted: March 11, 2017; Published: March 18, 2017

\begin{abstract}
Dessie Health Science College (DHSC) uses manual process system for the store. When customers need to borrow an item, and return the borrowed item they must go to the office and record what they want manually, that's way it is making the process too late. Which requires the employee to use paper based recording files to know the status of each customer and to perform the process in the system. The paper includes three chapters or phases. The first phase covers the introduction, which contains background, Existing system study, proposed system, objective of the project, benefits of the project, scope, methodology and significant of the project. The second phase covers the system features which contain existing system description, hardware requirement, software requirement, user requirement, system requirement, functional requirement, non-functional requirement, use case diagram, Use case description, activity diagram and sequence diagram. The third phase covers system design which include Deployment diagram, user interface design, ER diagram and Algorism design.
\end{abstract}

Keywords: Store Management, HTML, SQL, PHP

\section{Introduction}

The Dessie Health Science College (DHSC) store is giving an important service for its community which is found in that College. The properties of the store are acquired from donation or supplier with appropriate procurement these properties are distributed based on formal request forms. The current system gives vast service however it uses manual management system which leads the system to be inefficient. As part of the effort to bring efficient and modern store management system in DHSC, the new system should be designed and implemented that enables properties to be controlled and managed properly.

\subsection{Existing System Study}

The existing store management system is functioning using manual system. This manual system in which all the activities are carried out the following problems

- Materials are recorded issued and returned manually through long steps.

- Searching and getting available items are requested for use by staff takes long time and it is boring.

- Employees couldn't get a clearance in a fast because of the store manual record checking systems.
- Getting necessary report about the properties is difficult and takes long time.

- And expect to find out more problems in the existing system during study.

\subsection{Proposed System}

The proposed online store management system that attempts to replace the manual system has the following nature.

- The system can record any new item issue requested items with appropriate specification and category.

- The system generates a unique ID for each new fixed asset which is added to the database.

- The system can enable to search items that are available in the store house and use.

- It shortens the step by step processes in delivering or returning items.

- It generates up to date report at any time for decision makers for budget allocation and controlling.

- The system has database security. Since each worker in the store house has its own privilege to do their allowed operation on the database. 


\subsection{Objectives of the Project}

\subsubsection{General Objectives}

The main objective of the project is to explore the overall existing system of DHSC store management and to develop web based store management system for the existing system.

\subsubsection{Specific Objectives}

In Order to achieve the general objective, the following specific objectives are needed.

- Understand Manual process and its efficiency of the existing system.

- Review the current system to know the problem.

- Identify functional and nonfunctional requirements.

- Propose possible solutions for current system.

- Model the new system using object oriented methodologies.

- Finally implement and test the new system.

\subsection{Scope}

In this project occupied in the assessment of the existing system and identifying the problems of DHSC store management system. The proposed possible alternative solutions which can help to choose the best feasible solution and design an efficient online system for DHSC store management system.

\subsection{Beneficiaries of the Project}

Employers: - Dessie Health Science College, store workers

Staffs: - Administrative staffs, Instructors, Technical assistance of the schools

Student: - disable students, student union (for some clubs that are found in the College)

\subsection{Methodology}

Initially there will be continuous discussion with the entire store worker to get detail information about the store through interviewing and physical observation. To see how the current system works, the problem associated with the current system, skill that is needed by the store management and workers to reduce the problem that they are facing at present. The implemented of the system will be user friendly and built in PHP, HTML, JAVA SCRIPT, CSS programming language and the database. The approach going to implement will be structured query language (MY-SQL) server which will be more appropriate to store database and queries.

\subsection{Significance of the Project}

- Unauthorized person will be out of service

- Each task is performed easily

- Can perform many tasks in short period of time

- Every staff will be participant

- Change the manual system of the organization to computerized system

- Reduce unnecessary resource wastage.

- Reduce employee overload work.
- System gives fast service to the customer

\section{Existing System Description}

The existing store management system currently is functioning using manual system. Firstly, the user requests their needs to the purchaser and the purchaser approves the request. And also, the store manager checks the item whether it found in the system or not. If the requested item is existed, the user fills the form and take the item that he/she need. But if the requested item is existed, store manager permitted to the purchaser to buy the requested item and the manager announce to the user the item you need is coming.

\subsection{System Features}

\subsubsection{Hardware Requirement}

- Window XP server 2003, 2008: with the following attributes:

- Minimum 512 MB Memory

- Printer: To have a hard copy for the data.

- Keyboard: To give input to the computer.

\subsubsection{Software Requirement}

The client PC running the system may use any of the following operating system:

- Windows

- The client PC may use one of the following browsers:

- Internet Explorer

- Commit Bird

- Mozilla Firefox

- Google chrome....... etc.

But the system needs to fulfill the following software:

- Operating system: MS-window 2003, 2008 server will be used for the system.

- Database management software (DBMS): is the mandatory one for the new system. To implement the database easily, (MySQL) is recommended.

- Application software: to develop user and administrative interface it also used for connecting to the database, Most MS-Office applications are appropriate.

- PhpMyAdmin: choose PHP scripting language which aims at providing the user with an interface that is easy to learn and attractive.

- Macromedia Dreamweaver and notepad++: to edit the PHP code.

\subsubsection{User Requirement}

- The user interface shall be menu driven, it shall provide dialog boxes; help screens, drop down lists, radio buttons, check boxes and text boxes for user input.

- The navigation from one screen to the other must be easy.

- Necessary material for using the system will easy to the customer.

- Customers must fullfil the business rule to apply registration. 
- The store keeper can check the items that are taken by the staffs.

\subsubsection{System Requirement}

A requirement specification is an agreement between the end user and the system developer.

A. Functional Requirements

- Log on: the system validates the store staff to use the system.

- Receive Item: the system allows the store keeper to enter a new item which comes from deliverer or donor at the acquisition time.

- Approve Request: the system allows the store administrator to search the availability of the items in the store before approving the requested item availability and relevance.

- Cancel Request: the system allows the store administrator to cancel the approved request before the items are issued by the store keeper using approval number.

- View Report: the system allows the store administrator and store keeper to overview and report from the system database monthly.
- Request Item: the staff request item to the system.

- Search Item: the staffs search the item whether it found or not in the store.

- The system generates error message that says the number of certain item become zero

B. Non-Functional Requirements

- Maintenance: The store Management System is being developed in PHP. PHP is an object-oriented programming language and shall be easy to maintain

- Portability: -The Store Management System shall run in any Microsoft Windows environment that contains PHP Runtime and the Microsoft Access database.

- Reliability: - The Store Management System service should not access without authenticate user.

- Standards Compliance: - The graphical user interface of the system shall have easily understood to the user (have consistent look and feel graphical user interface).

- Performance: -Acceptable response times for system functionality.

- Security: - Access to the various subsystems will be protected by a user log in screen that requires a user name and password.

\subsection{Analysis Models}

\subsubsection{Use Case Diagram}

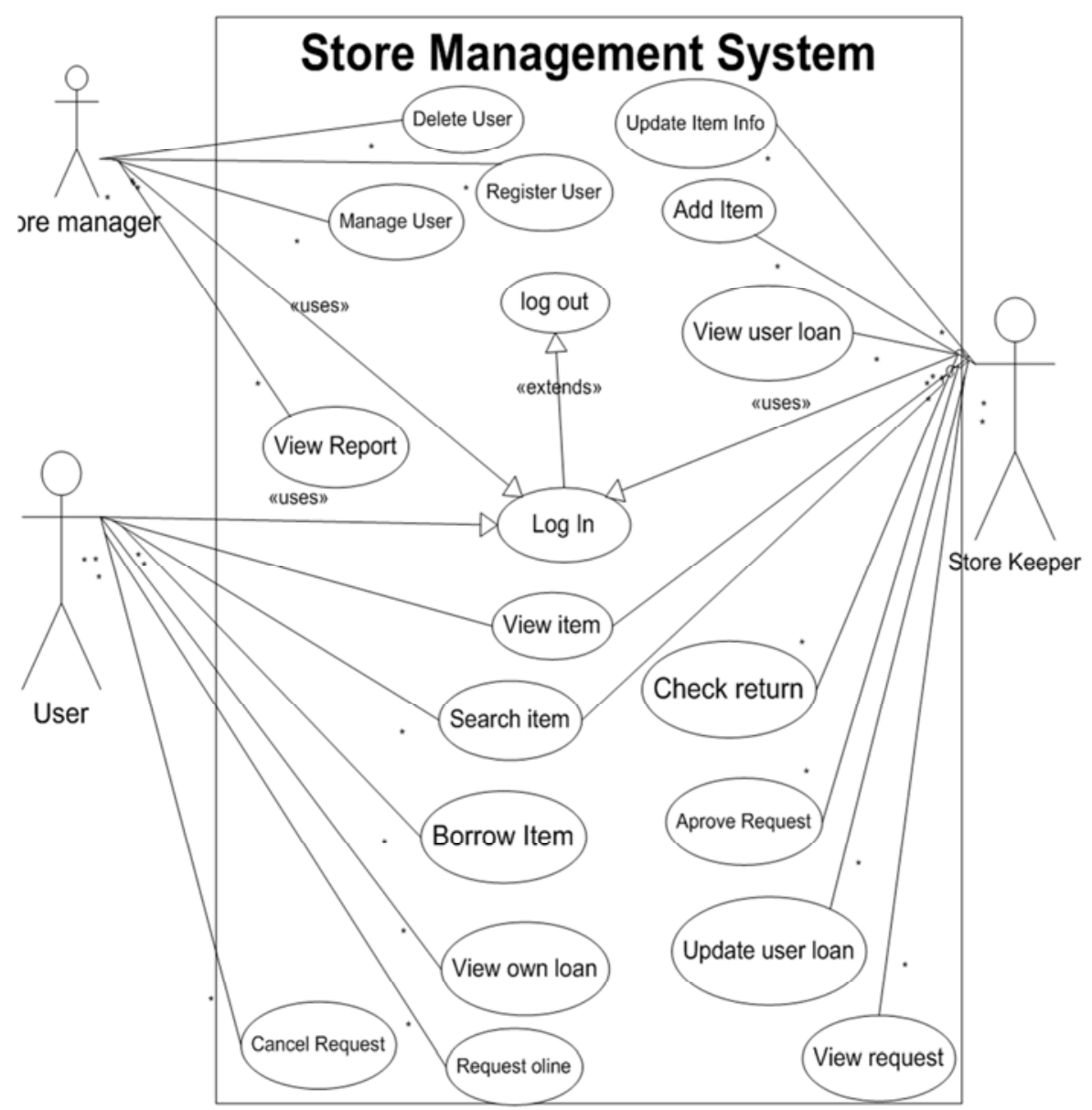

Figure 1. Use case diagram. 
Use case description

A use case is a methodology used in system analysis to identify, clarify, and organize system requirements. The use case is made up of a set of possible sequences of interactions between systems and users in a particular environment and related to a particular goal. Use case is a list of steps, typically defining interactions between a role (known in UML as an actor) and a system, to achieve a goal. The actor can be a human or an external system.

Table 1. Log In

\begin{tabular}{ll}
\hline Use case name & Login \\
\hline Participating actor & Store administrator, store keeper, and user. \\
Entry condition & The user opens the home page of the system. \\
& 1. The user wants to log in into the system. \\
& 2.The system displays the form \\
Basic course of action & 3. The user inputs his/her username and password into the system. \\
& 4. The system verifies that the user is eligible to log in into the system (account checking in the database). \\
& 5. The user login into the system. \\
Alternative course of action & The system updates the user period of time and the number of log in failure. \\
Exit condition & When the user clicks log off button. \\
Pre-condition & The user has a user name and password. \\
Post condition & The user login into the system and do in the system the allowed operation \\
\hline
\end{tabular}

\subsection{Activity Diagram}
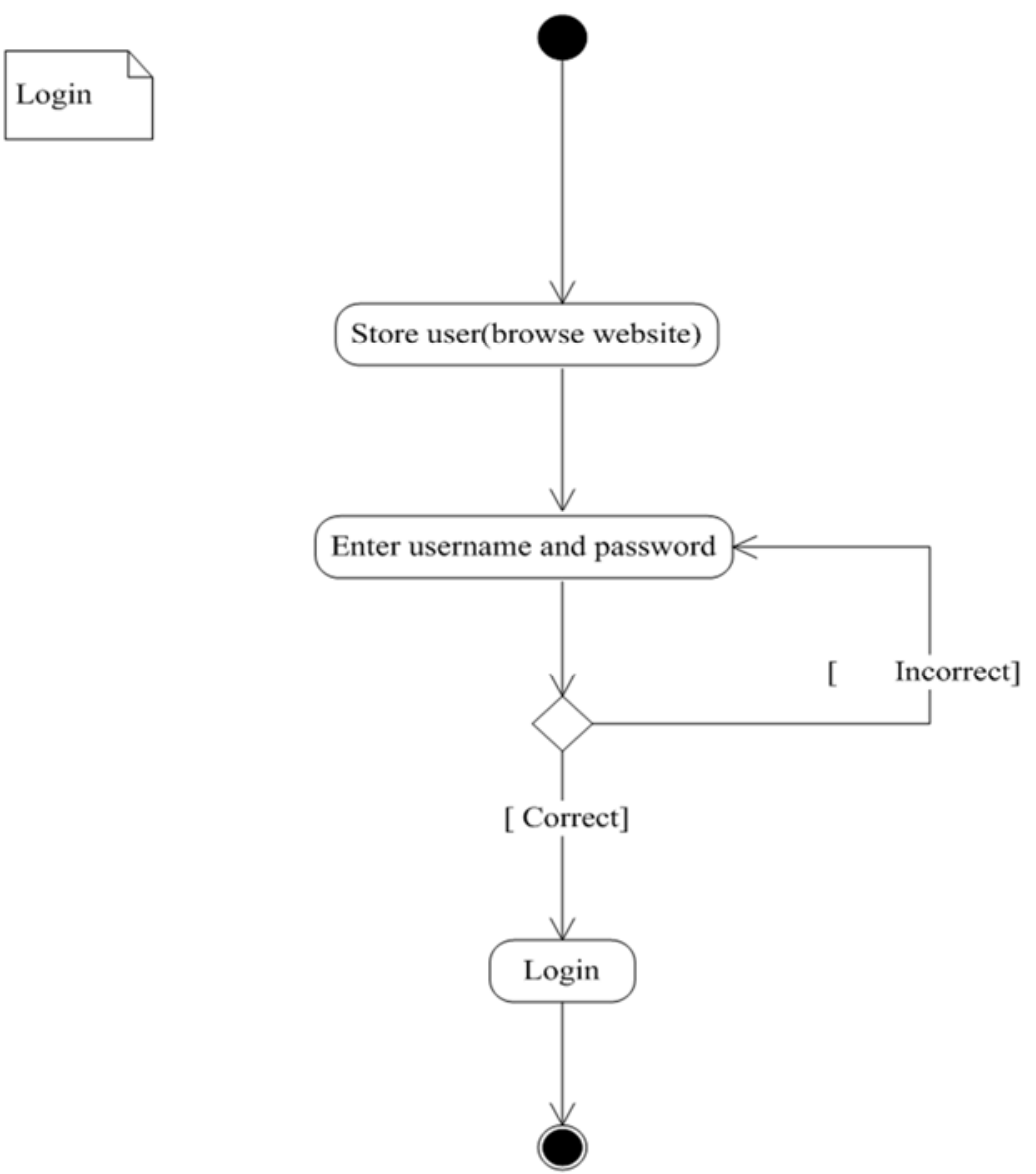

Figure 2. Log in activate diagram.

\section{System Design}

Our project system design includes deployment diagram, class diagram, graphical user interface, E-R diagram and algorithm design. 


\subsection{Deployment Diagram}

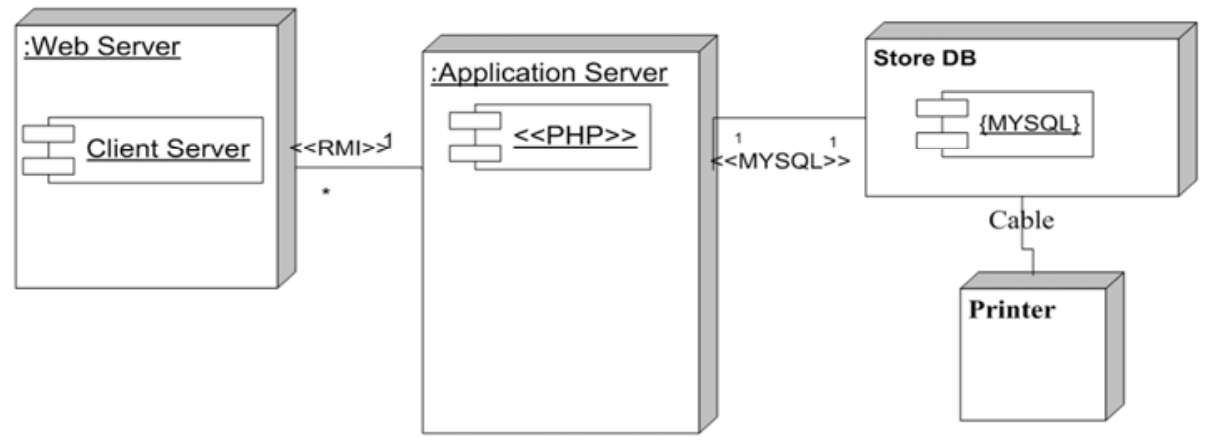

Figure 3. Deployment Diagram.

\subsection{Architectural Design}

Class diagram

- Staff: a person who get any service from the store.

- Store Keeper: a person who receives new items and receives returned items.

- Store Administrator: a person who creates username, password for the users.

- Item: an item is any goods which are used by the staffs. And it is divided as renewable and non-renewable items

- Request: request that is sent by the staffs and managed by the store keeper.

- Loan: it is used to see the staffs their own loan and to see the store keeper the loan of their user

- Account: account is created by the store admin and used by the staffs and store workers.

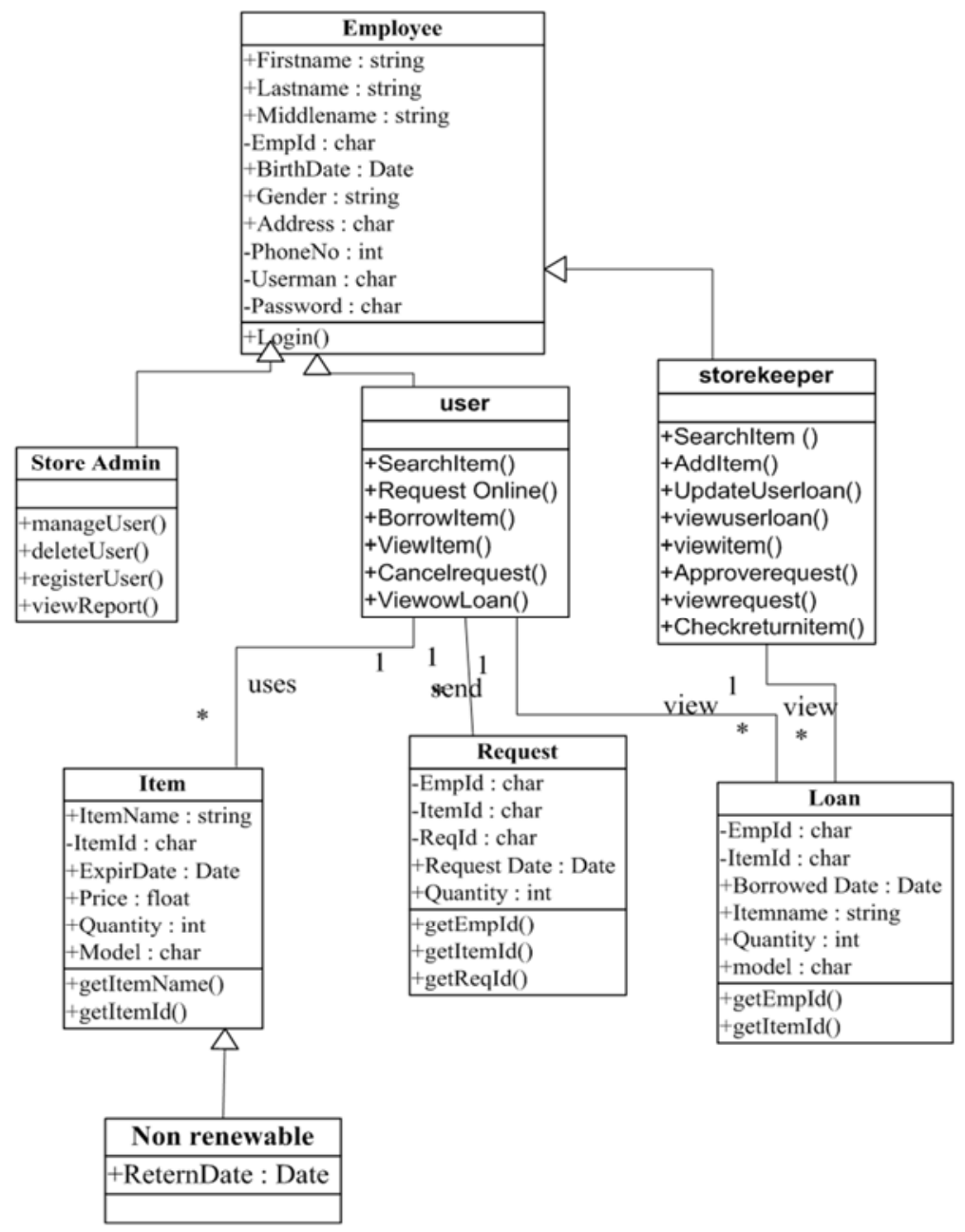

Figure 4. Class diagram. 


\section{User Interface Design}

This user interface design shows the sample of this project implementation part.

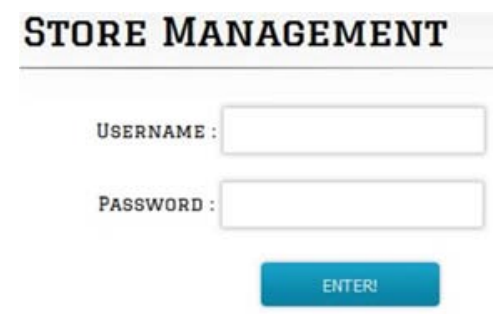

Figure 5. Login page.

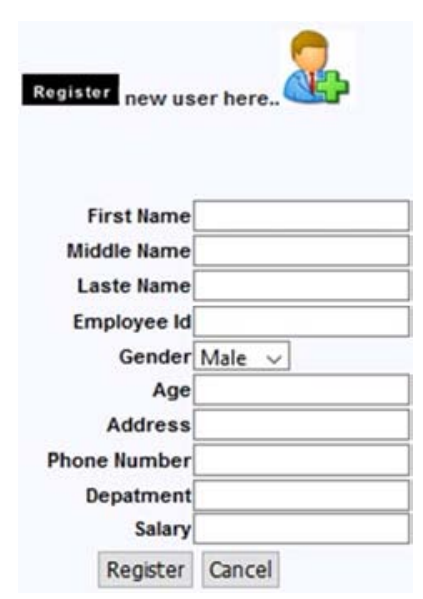

Figure 6. Register new user.

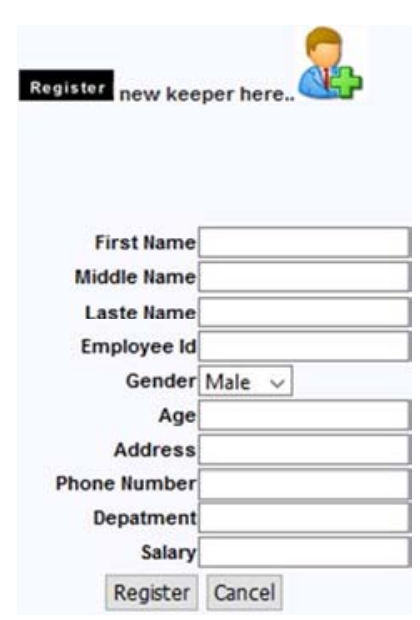

Figure 7. Register New keeper.

\section{References}

[1] Zhibing Liu, H. W., Hui Zan, Design and implementation of student information management system. International symposium on intelligence information processing and trusted computing, 2010

[2] Malan, R., Functional Requirements and Use Cases.

[3] Lane, D.a.W., H. E., Web Database Applications with PHP and MySQL. 2004: O'Reilly.

[4] Greenspan, J., Wall, D. and Bulger, B., MySQL/PHP Database Applications. 2004.

[5] Williams, J., New Hardware Purchasing Guidelines 2012.

[6] Grady Booch, R. A. M., Michael W. Engle, Bobbi J. Young, Ph.D., Jim Conallen and Kelli A. Houston, Object-Oriented Analysis and Design with Applications. 3rd ed.

[7] Swatman, L. D. P., The Use of Object-Oriented Models In Requirements Engineering: A Field Study. 1998.

[8] Rumbaugh, J., Jacobson, I., \& Booch, G., The Unified Modeling Language Reference Manual: the definitive reference to the UML from the original designers. 2003, Singapore: Pearson Education Inc.

[9] Grady Booch, R. A. M., Michael W. Engle, Bobbi J. Young, Ph.D., Jim Conallen and Kelli A. Houston, Object-Oriented Analysis and Design with Applications. 3rd ed.

[10] Zhi-gang YUE, Y.-w. J., The development and design of the student management system based on the network environment. 2010: International Conference on Multimedia Communications, 978-0-7695-4136-5/10 2010 IEEE.

[11] Lane, D.a.W., H. E., Web Database Applications with PHP and MySQL. 2004: O'Reilly.

[12] Angell, I. O. \& Smithson, S. 1991. Information Systems management: Opportunities and Risks. London: Macmillan Education Ltd.

[13] Berners-Lee, T. J. 1992. "World-Wide Web: Information Universe", Electronic: Research, Applications and Policy.www.w3.org/People/Berners-Lee/Longer.html [accessed on 24th May 2011]c 